\title{
Rancang Bangun Kontroller Virtual Reality dengan Magnetometer Akselerometer Giroskop (MARG) dan Filter Madgwick
}

\author{
Rachmad Sudibyo Danu S, Melania Suweni Muntini, dan Iim Fatimah \\ Jurusan Fisika, Fakultas Matematika dan Ilmu Alam, Institut Teknologi Sepuluh Nopember (ITS) \\ Jl. Arief Rahman Hakim, Surabaya 60111 Indonesia \\ e-mail: danu166@gmail.com
}

\begin{abstract}
Abstrak-Pada studi ini telah dibuat dan dianalisis kontroller Virtual Reality berbasis sensor magnetometer HMC5883L, akselerometer beserta giroskop MPU6050, dan mikrokontroller Arduino ATMEGA328. Keluaran dari sistem berupa nilai orientasi sudut putar yaw, pitch dan roll, kemudian diberikan variasi konstanta $\beta$ untuk mengetahui pengaruhnya terhadap nilai keluaran.. Pengujian sistem dilakukan pada keadaan statis dan dinamis. Dari hasil pengujian semakin besar nilai konstanta $\beta$, semakin cepat waktu untuk mencapai keadaan steady-state. Nilai optimum dari variasi konstanta $\beta$ yang diberikan adalah 0.05 dikarenakan memiliki Root Mean Square Error yang terkecil diantara variasi lainnya.
\end{abstract}

Kata Kunci-Filter Madgwick, Konstanta $\beta$, Nilai Orientasi dan Root Mean Square Error.

\section{PENDAHULUAN}

$\mathrm{V}$ IRTUAL REALITY (VR) adalah istilah yang digunakan untuk menggambarkan lingkungan tiga dimensi yang dihasilkan oleh komputer yang dapat dieksplorasi dan berinteraksi dengan objek virtual. VR memanfaatkan indra penglihatan dan gerakan seseorang untuk merasakan sensasi dunia nyata di dunia maya. Untuk itu diperlukan seperangkat alat untuk memanipulasi persepsi indra seseorang. Alat ini berupa Headset VR yang umumnya terdiri dari layar, speaker dan sensor yang dipakai dikepala pengguna. Juga kontroller VR yang bertujuan mengendalikan ataupun berinteraksi dengan objek virtual.

Perkembangan smartphone yang pesat banyak dimanfaatkan oleh pengembang VR. Mereka memanfaatkan sensor-sensor yang terdapat di smartphone untuk menambahkan fungsi smartphone sebagai headset VR dengan begitu banyak kalangan yang dapat merasakan teknologi VR. Namun, kekurangan menggunakan teknologi VR dengan smartphone saat ini adalah terbatasnya interaksi antara penggunanya dan objek virtual.

Dalam sistem kerjanya, Headset VR maupun kontroller VR memanfaatkan sensor Inertial Measurement Unit (IMU) sebagai input untuk berinteraksi dengan dunia maya. Sensor IMU merupakan gabungan dari sensor-sensor yang terdiri dari sensor akselerometer dan giroskop. Keluaran dari sensor ini dapat mengukur sudut putar dengan menerapkan serangkaian algoritma. Tidak jarang sensor IMU dipadu dengan sensor magnetometer untuk menambah akurasi keluaran. Hasil nilai sudut putar yang didapat digunakan untuk menggerakan gambar pada Headset VR.
Sedangkan pada kontroller VR digunakan untuk berinteraksi dengan objek virtual yang ditampilkan pada Headset VR.

Banyak metode yang disajikan untuk mendapatkan nilai orientasi, seperti filter kalman. Namun, filter kalman membutuhkan banyak memori. Pada tahun 2010 Sebastian O.H. Madgwick memperkenalkan filter efisien dengan mengembangkan filter mahony yang kemudian dikenal filter madgwick. Filter ini memiliki kelebihan tidak membutuhkan banyak memory, efektif pada lowsampling rates $(10 \mathrm{~Hz})$ dan lebih akurat dari filter kalman[1].

IMU merupakan gabungan dari beberapa sensor dan memiliki beragam jenis. Diantaranya adalah sensor akselerometer dan giroskop, gabungan kedua sensor ini disebut IMU 6 degree of freedom (DOF), dikarenakan memilki tiga sumbu pengukuran akselerometer dan tiga sumbu pengukuran giro. Jenis lain terdapat gabungan sensor magnetometer, akselerometer dan giroskop atau disebut juga Magnetic Angular Rate and Gravity (MARG) atau IMU 9 DOF.

Jenis sensor disesuaikan dengan kebutuhan. IMU 6 DOF mengukur sudut putar dengan acuannya adalah nilai gravitasi. IMU 9 DOF mengukur orientasi dengan acuannya gravitasi dan kutub utara medan magnet bumi. Kelebihan dari IMU 9 DOF memiliki output yang lebih stabil jika dioperasikan dengan filter madgwick, sedangkan IMU 6 DOF output nya masih tedapat drift pada salah satu sumbunya.

Orientasi masing-masing sumbu (yaw, pitch, roll) secara matematis bisa didapatkan dengan cara mengintegralkan kecepatan sudut dari setiap sumbu, yaitu dengan menggunakan sensor giroskop. Namun dengan menggunakan data dari giroskop sendiri apabila diintegralkan akan menambah nilai error sehingga nilai yang didapat tidak akurat. Untuk itu, alasan digunakan IMU untuk mengukur orientasi adalah untuk mengatasi kekurangan dari giroskop. Sifat drift dari giroskop dikarenakan dalam pengukurannya giroskop tidak mempunyai titik acuan, disini akselerometer dan magnetometer akan mengukur gravitasi dan medan magnet bumi sebagai acuan untuk mengatasi drift.

\section{PERANCANGAN SISTEM}

Diagram blok perancangan sistem IMU dapat diamati pada Gambar 1. Akselerometer 3 aksis digunakan untuk mendeteksi vektor gravitasi Bumi, Magnetometer 3 aksis digunakan untuk mendeteksi vektor arah Utara, keduanya dilihat dari sudut pandang koordinat lokal. Giroskop 3 
aksis digunakan untuk mendapatkan kecepatan sudut yang digunakan untuk meng update posisi vektor gravitasi dan utara, kemudian semua masukkan tersebut diolah dalam Algoritma filter Madgwick dengan luaran ahir berupa sudut yaw, pitch dan Roll.

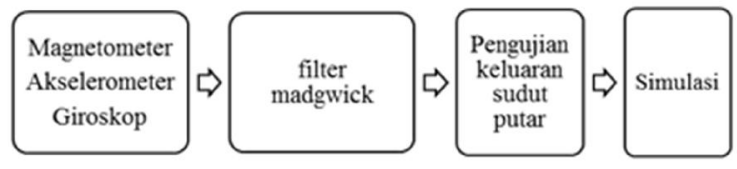

Gambar 1. Perancangan umum sistem

\section{A. Perancangan Hardware}

Kontroller VR menggunakan sensor MPU-6050 dari InvenSense dan HMC5883L dari Honeywell yang dijadikan dalam satu modul. Sensor MPU-6050 terdiri dari MEMS akselerometer dan MEMS giro yang digabung menjadi satu IC. Dengan range akselerometer yang digunakan sebesar $\pm 2 \mathrm{~g}$ dan gyro $\pm 250^{\circ} / \mathrm{s}$ sedangkan sensitivitas akselerometer sebesar $16,384(\mathrm{LSB}) /(\%)$ dan gyro $131(\mathrm{LSB}) /\left({ }^{\circ} / \mathrm{s}\right)$. Beberapa fitur tambahan dari MPU-6050 adalah terdapat fitur self-test untuk mengkondisikan pengukuran sensor dalam keadaan normal, dan kalibrasi memanfaatkan DMP yaitu unit processing yang terdapat pada internal sensor.

HMC5883L merupakan magnetometer tiga sumbu yang didesain untuk mengukur medan magnet. Dengan range \pm 8 Gauss dan resolusi sampai dengan 5 milliGauss Selain itu sensor ini termasuk low power consumption.

Untuk melakukan pengambilan data dari ketiga sensor beserta komputasi digunakan papan mikrokontroller Arduino berbasis ATmega 328. Mikrokontroller ini bekerja pada tegangan 5 Volt, dengan Flash memory $32 \mathrm{~KB}$, SRAM $2 \mathrm{~KB}$, dan clock speed $16 \mathrm{MHz}$. Untuk sumber tegangan Arduino dan komunikasi serial digunakan papan FTDI yang kemudian terhubung pada USB laptop. Gambar 2 adalah skema kontroller VR.

\section{B. Perancangan Software}

Arduino IDE untuk mengakses sistem sensor dan melakukan komputasi estimasi nilai orientasi sumbu yaw, pitch dan roll dengan menggunakan filter madgwick. Data yang telah diolah kemudian ditampilkan kedalam Serial Monitor. Gambar 3 merupakan diagram alir dari perancangan perangkat lunak sistem sensor.

Pengukuran dari giroskop digunakan untuk mengestimasi nilai orientasi, sedangkan pengukuran dari akselerometer dan magnetometer yang telah terkalibrasi kemudian dinormalisasi. Selanjutnya data dari akselerometer dan magnetometer digunakan untuk menentukan faktor koreksi dari nilai orientasi yang didapat dari pengukuran giroskop.

Setelah estimasi nilai orientasi giroskop dan faktor koreksi didapat, kemudian dimasukkan kedalam algoritma sensor fusion. Nilai orientasi yang baru adalah nilai orientasi lama yang dikurangi dengan faktor koreksi yang diberi bobot konstanta $\beta$ dan dikalikan dengan periode sistem melakukan satu perhitungan. Konstanta $\beta$ divariasikan untuk mengetahui pengaruh terhadap keluaran system, variasi konstanta $\beta$ yang digunakan adalah $0.01,0.05,0.1,0.5,1$ dan 2 . Setelah nilai orientasi didapat kemudian dilakukan konversi dari bentuk quaternion menjadi sudut putar[2].

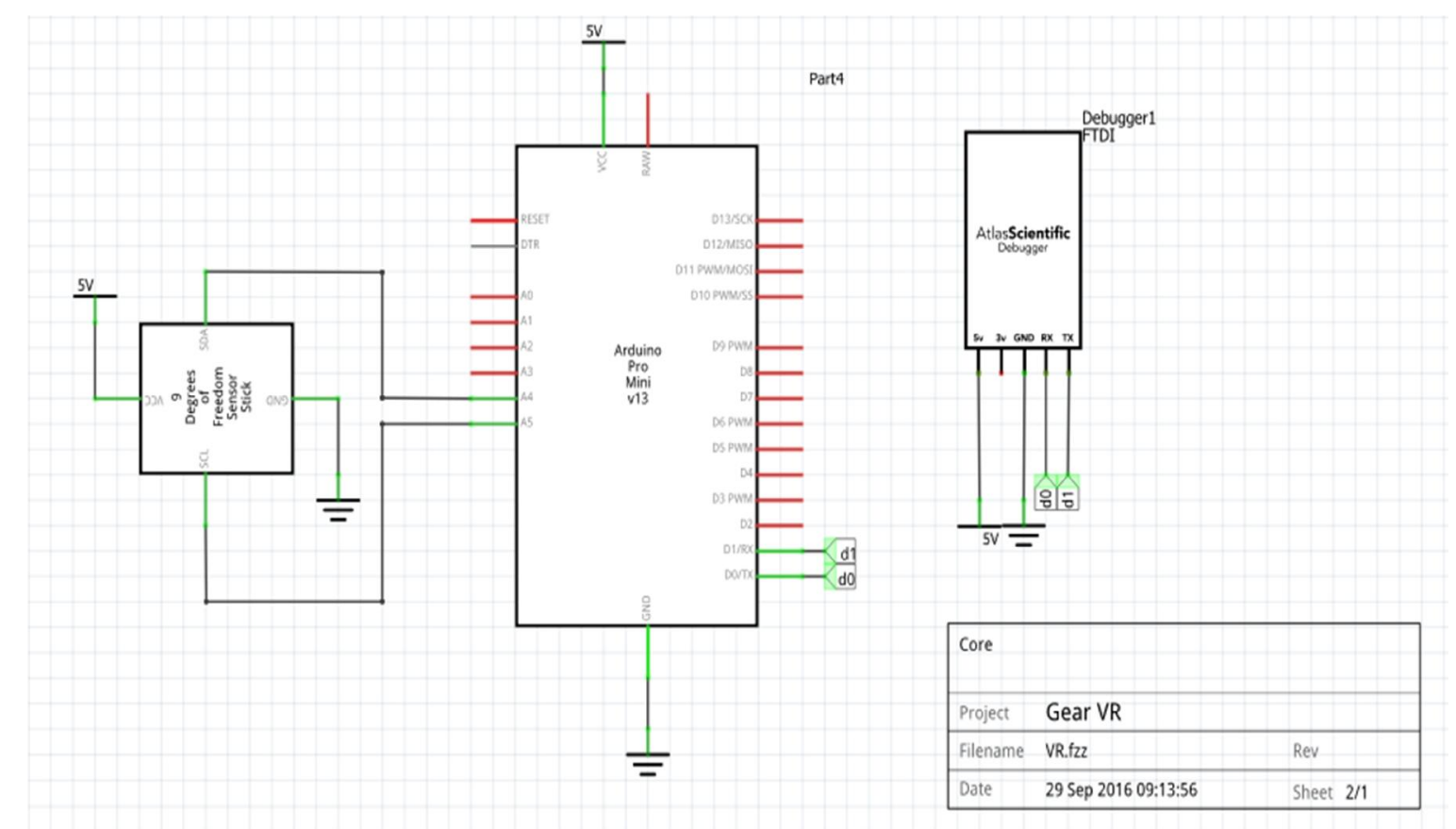

Gambar 2. Skema Kontroller VR 


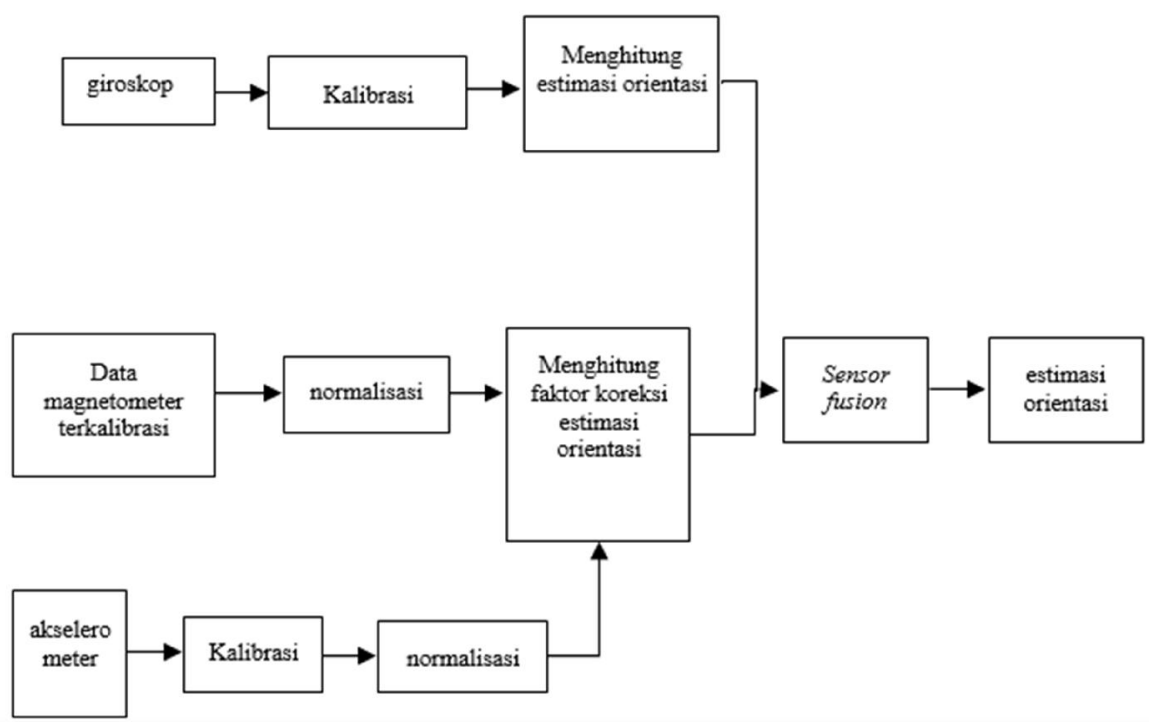

Gambar 3. Diagram blok sistem kontroller VR

\section{PENGUJIAN DAN ANALISIS}

Pada bab ini akan dipaparkan hasil pengujian sistem beserta analisisnya. Pengujian dilakukan dengan menggunakan gimbal elektronik seperti pada Gambar 4. Gimbal elektrik yang digunakan merupakan $3 d$ printer yang telah dimodifikasi yang hanya dioperasikan satu motornya saja.

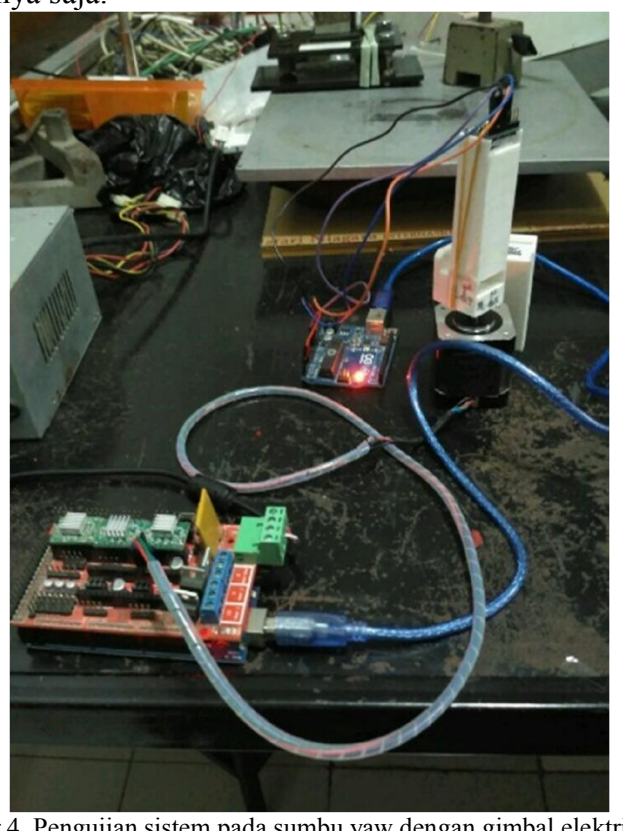

Gambar 4. Pengujian sistem pada sumbu yaw dengan gimbal elektrik

\section{Analisis Performa Kondisi Statis dan Dinamis}

Untuk mengetahui performa dari sistem yang digunakan dengan menggunakan filter madgwick dihitung Root Mean Square error (RMSe). Kondisi statis merupakan kondisi ketika sensor tidak diberikan pergerakan dan kondisi dinamis ketika sensor digerakan dengan kecepatan 5,5\% detik untuk roll dan $6 \%$ detik untuk sumbu /detik untuk sumbu yaw dan pitch. Hasil nilai RMSe pada keadaan statis dan dinamis dirangkum pada tabel 1 dan 2.
Tabel 1.

RMSe kondisi statis

\begin{tabular}{cccc}
\multicolumn{4}{c}{ RMSe kondisi statis } \\
\hline \hline \multirow{2}{*}{ beta } & \multicolumn{3}{c}{ RMSe (derajat) } \\
\cline { 2 - 4 } & yaw & Pitch & roll \\
\hline 0.01 & 0.1625 & 0.1512 & 0.1897 \\
0.05 & 0.1585 & 0.1560 & 0.1786 \\
0.1 & 0.2298 & 0.1720 & 0.1477 \\
& & & \\
0.5 & 0.2579 & 0.2079 & 0.1907 \\
1 & 0.1863 & 0.3408 & 0.3475 \\
2 & 0.2025 & 0.6532 & 0.7597 \\
\hline \hline
\end{tabular}

Tabel 2.

RMSe kondisi dinamis

\begin{tabular}{cccc}
\multicolumn{4}{c}{ RMSe kondisi dinamis } \\
\hline \hline \multirow{2}{*}{ beta } & \multicolumn{3}{c}{ RMSe (derajat) } \\
\cline { 2 - 4 } & yaw & pitch & roll \\
\hline 0.01 & 1.1716 & 2.2224 & 3.9857 \\
0.05 & 0.3365 & 1.8993 & 2.2363 \\
0.1 & 0.4916 & 1.8412 & 5.5798 \\
0.5 & 1.1501 & 1.2552 & 4.3732 \\
1 & 0.9752 & 1.3923 & 5.1141 \\
2 & 1.5291 & 1.9417 & 5.1186 \\
\hline \hline
\end{tabular}

Hasil pengujian kondisi statis menunjukkan bahwa dari semua variasi yang digunakan RMSe yang didapat kurang dari $0.75^{\circ}$ menunjukkan bahwa keluaran yang didapat cukup stabil dan akurat. Untuk hasil pengujian kondisi dinamis dari variasi yang diberikan didapat nilai RMSe terkecil pada sumbu yaw adalah $0.3365^{\circ}$ untuk sumbu pitch $1.2552^{\circ}$ dan untuk sumbu roll $2.2363^{\circ}$.

Pada variasi beta $0.01,0.1,0.5,1$ dan 2 nilai RMSe yang didapat relatif lebih kecil dari variasi beta 0.05 . Ketidaksesuaian estimasi yang diperoleh dari nilai referensi salah satunya dipengaruhi dari konstanta $\beta$ yang akan dibahas pada subbab selanjutnya.

\section{Pengaruh Konstanta $\beta$}

Mikrokontroller digunakan untuk melakukan komputasi melakukan iterasi perhitungan untuk mendapatkan estimasi nilai orientasi yang optimum, untuk itu diperlukan waktu agar nilai estimasi yang didapat memiliki faktor koreksi yang lebih kecil dari perhitungan estimasi sebelumnya. Kecepatan 
mengestimasi atau sampling rate nilai orientasi tergantung dari konfigurasi mikrokontroller dan sistem yang digunakan, pada percobaan ini kecepatan perhitungan yang digunakan adalah 138 kali per detik $(138 \mathrm{~Hz})$. Pengukuran sampling rate berdasarkan kinerja maksimum dari mikrokontroller yang digunakan.

Waktu yang dibutuhkan untuk mencapai keadaan steady-state pada kondisi statis berbeda-beda. Untuk konfigurasi sistem yang sama dengan nilai $\beta$ yang berbeda didapatkan waktu yang berbeda. Ketika nilai $\beta$ semakin kecil, waktu yang dibutuhkan untuk mencapai keadaan steady-state semakin besar, sebaliknya jika nilai $\beta$ semakin besar waktu yang dibutuhkan untuk mencapai keadaan steady-state semakin kecil. Hal ini dikarenakan nilai konstanta $\beta$ mempengaruhi besarnya faktor koreksi untuk mengestimasi nilai orientasi yang baru.

Tabel 3.

Pengaruh konstanta $\beta$ terhadap waktu kalibrasi pada kondisi statis

\begin{tabular}{cc}
\hline \hline beta & waktu kalibrasi(detik) \\
\hline 0.01 & 5 \\
0.05 & 4.2 \\
0.1 & 4.1 \\
0.5 & 3.4 \\
1 & 2.5 \\
2 & 1.6 \\
\hline \hline
\end{tabular}

Semakin kecilnya waktu kalibrasi tidak menunjukkan bahwa sistem yang dibuat semakin baik. Dari variasi $\beta$ yang diberikan, nilai $\beta$ optimum ketika bernilai 0.05 yaitu sebesar $0.1643^{\circ}$ pada kondisi statis dan $1.4906^{\circ}$ pada kondisi dinamis. nilai optimum ditentukan berdasarkan variasi nilai konstanta $\beta$ yang menghasilkan nilai estimasi orientasi rata-rata terkecil dari ketiga sumbu yaw, pitch dan roll seperti yang terlihat pada gambar 5. Semakin besar nilai $\beta$ dari nilai optimum, nilai keluarannya memiliki rentang fluktuasi yang lebih besar, mengakibatkan ketika keluaran ini disimulasikan akan terlihat tidak stabil yang menunjukkan berkurangnya akurasi perhitungan estimasi orientasi seperti pada hasil pengujian kondisi dinamis pada sumbu roll. Sebaliknya jika nilai $\beta$ yang digunakan lebih kecil dari nilai optimum, nilai keluarannya memiliki rentang fluktuasi yang lebih kecil sehingga terlihat lebih stabil namun membutuhkan waktu yang lebih lama untuk mendapatkan nilai estimasi orientasi yang optimum, pada kondisi dinamis mengakibatkan terdapat jeda antara nilai estimasi orientasi keluaran sistem dan nilai orientasi gimbal elektrik.

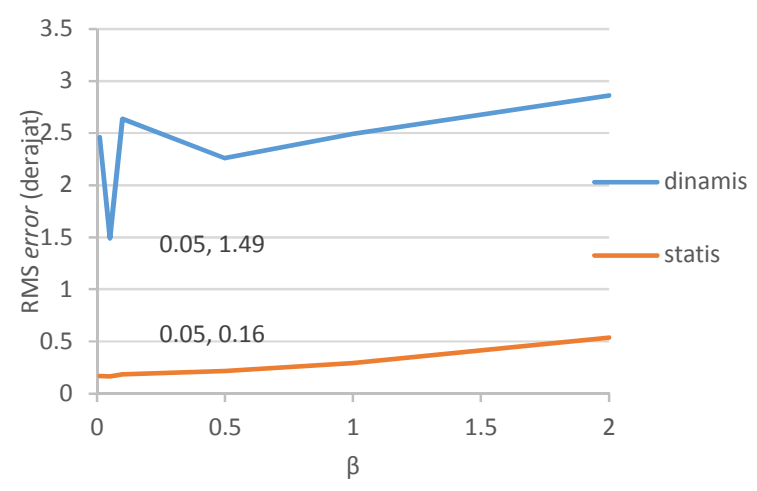

Gambar 5. Pengaruh konstanta $\beta$ terhadap rata-rata RMSe yang dihasilkan pada kondisi statis dan dinamis.

\section{KESIMPULAN}

Berdasarkan hasil pengujian dapat disimpulkan bahwa konstanta $\beta$ mempengaruhi performa sistem. Waktu kalibrasi sistem semakin besar jika nilai konstanta $\beta$ semakin besar, semakin cepat waktu untuk mencapai keadaan steady-state. Dari variasi konstanta $\beta$ yang diberikan, nilai optimum konstanta $\beta$ adalah 0,05 dikarenakan memiliki rata-rata nilai RMSe yang terkecil diantara variasi konstanta $\beta$ lainnya.

\section{DAFTAR PUSTAKA}

[1] Sebastian O. H. Madgwick. An efficient filter for inertial and inertial/magnetic sensor arrays.2010. IEEE ICORR, June 2011, pp. 1-7.

[2] J. B. Kuipers. Quaternions and Rotation Sequences: A primer with Applications to Orbits, Aerospace and Virtual Reality. Princeton University Press, 1999. 